\title{
Transcriptomic and functional analyses reveal an antiviral role of autophagy during pepper mild mottle virus infection
}

\author{
Yubing Jiao ${ }^{1 \dagger}$, Mengnan $\mathrm{An}^{1 \dagger}$, Xiaodong $\mathrm{Li}^{2}$, Man Yu${ }^{1}$, Xiuxiang Zhao ${ }^{1}$, Zihao Xia ${ }^{1 *}$ (D) and Yuanhua $\mathrm{Wu}^{1{ }^{*}}$
}

\begin{abstract}
Background: Pepper mild mottle virus (PMMoV) is a member in the genus Tobamovirus and infects mainly solanaceous plants. However, the mechanism of virus-host interactions remains unclear. To explore the responses of pepper plants to PMMoV infection, we analyzed the transcriptomic changes in pepper plants after PMMoV infection using a high-throughput RNA sequencing approach and explored the roles of host autophagy in regulating PMMoV infection.

Results: A total of 197 differentially expressed genes (DEGs) were obtained after PMMoV infection, including 172 significantly up-regulated genes and 25 down-regulated genes. The Gene Ontology (GO) and Kyoto Encyclopedia of Genes and Genomes (KEGG) pathway analyses revealed that most up-regulated DEGs were involved in plant abiotic and biotic stresses. Further analyses showed the expressions of multiple autophagy-related genes (ATGs) were increased after PMMoV infection in pepper and Nicotiana benthamiana plants. Through confocal microscopy and transmission electron microscopy, we have found that PMMoV infection in plant can induce autophagy, evidenced by the increased number of GFP-ATG8a fluorescent punctate and the appearance of double membrane autophagic structures in cells of $\mathrm{N}$. benthamiana. Additionally, inhibition of autophagy significantly increased PMMoV RNA accumulation and aggravated systemic PMMoV symptoms through autophagy inhibitor (3-MA and E64d) treatment and silencing of NbATG expressions by a Tobacco rattle virus-induced gene silencing assays. These results indicated that autophagy played a positive role in plant resistance to PMMoV infection.

Conclusions: Taken together, our results provide a transcriptomic insight into pepper responding to PMMoV infection and reveal that autophagy induced by PMMoV infection has an antiviral role in regulating PMMoV infection. These results also help us to better understand the mechanism controlling PMMoV infection in plants and to develop better strategies for breeding projects for virus-resistant crops.
\end{abstract}

Keywords: Pepper mild mottle virus (PMMoV), Pepper, Transcriptomic analysis, Autophagy, Nicotiana benthamiana, Defense response

\footnotetext{
*Correspondence: zihao8337@syau.edu.cn; wuyh09@syau.edu.cn

${ }^{\dagger}$ Yubing Jiao and Mengnan An contributed equally to this work.

${ }^{1}$ College of Plant Protection, Shenyang Agricultural University, Shenyang

110866, China

Full list of author information is available at the end of the article
}

C C The Author(s). 2020 Open Access This article is licensed under a Creative Commons Attribution 4.0 International License, which permits use, sharing, adaptation, distribution and reproduction in any medium or format, as long as you give appropriate credit to the original author(s) and the source, provide a link to the Creative Commons licence, and indicate if changes were made. The images or other third party material in this article are included in the article's Creative Commons licence, unless indicated otherwise in a credit line to the material. If material is not included in the article's Creative Commons licence and your intended use is not permitted by statutory regulation or exceeds the permitted use, you will need to obtain permission directly from the copyright holder. To view a copy of this licence, visit http://creativecommons.org/licenses/by/4.0/. The Creative Commons Public Domain Dedication waiver (http://creativecommons.org/publicdomain/zero/1.0/) applies to the data made available in this article, unless otherwise stated in a credit line to the data. 


\section{Background}

Pepper (Capsicum annuum L.) is a solanaceous vegetable crop with a great economic value worldwide [1]. Pepper is known to be vulnerable to fungal, bacterial and viral pathogens. For example, virus infection can cause serious pepper yield and quality reductions under both field and protective cultivation conditions [2]. To date, about 13 plant viruses have been reported to infect pepper crops worldwide [3, 4]. Among these known plant viruses, pepper mild mottle virus (PMMoV) is a great threat to pepper production, due mainly to its high contagious nature and long persistence in soil [5].

PMMoV is a positive-sense single-stranded RNA (+ssRNA) virus in the genus Tobamovirus of the family Virgaviridae [6, 7]. The genome of PMMoV, which contains a m7GpppG cap structure at $5^{\prime}$ end and its 3 ' end could be folded into tRNA structure, consists of 6356-6357 nucleotides (nts) and encodes at least four proteins: $126-\mathrm{kDa}$ (p126) and 183-kDa (p183) replication-associated proteins sharing the same initiation codon, movement protein (MP) and coat protein (CP) [6]. PMMoV infection initially causes mild foliar mosaic symptoms followed by mottling and malformation of leaves and fruits, resulting in significant losses of pepper yield and cash values [8]. Moreover, PMMoV infection cause some human clinical illness such as fever, abdominal pains and pruritus [9]. This study was designed to identify host factor(s) that regulate PMMoV infection in pepper and can be utilized to develop effective PMMoV control strategies.

Viral infection in plant is a sophisticated process that involves many un-elucidated interactions between virus and host plant. It was reported that during virus initial invasion, host plant can activate signaling cascades to recognize the invading virus, and during virus infection, the host can alter the expressions of various metabolism-, signal transduction- and/or protein synthesisrelated genes to suppress virus further replication and spread [10]. We speculated that identifications of host factor(s) that can regulate host-pathogen interactions should provide useful insights into the mechanism controlling host defense responses to virus infection, and important molecular markers for future breeding projects of disease resistance [11]. Because host-virus interaction is complex and involves many physiological processes, transcriptomic analysis has become increasingly important for this type of study [12]. RNA sequencing (RNA-seq) is a powerful technique for the identifications of genes whose expressions can be altered during abiotic and biotic stresses. For example, RNA-seq has been used to study global gene expression profiles and signal transduction pathways involved in plant defense responses to various stresses, including virus infection [13-15]. Genome of pepper has recently been fully sequenced $[16,17]$. This valuable resource allows us to investigate transcriptomic changes during PMMoV infection in pepper plant.

Autophagy is an evolutionarily conserved intracellular degradation pathway in eukaryotes. It can transport cytoplasmic components, including proteins and dysfunctional organelles, to lysosomes (in animals) or vacuoles (in yeast and plants) for degradation [18, 19]. Autophagy has been reported to stabilize cells and organs, to regulate programmed cell death (PCD) [20], and to control plant development, regeneration, senescence, other biological processes, and responses to abiotic stresses [21]. Autophagy can also cause hypersensitive response (HR)-mediated cell death during initial plant responses to pathogens, and limit the spread of PCD beyond the initial infection site [22]. Moreover, autophagy is considered to participate in plant defense against virus infection through different mechanisms. For example, Neighbor of BRCA1 gene 1 (NBR1)-mediated selective autophagy pathway can inhibit cauliflower mosaic virus (CaMV) infection via binding to viral capsid protein and virus particles [23]. Autophagy can target the virulence factor $\beta C 1$ of cotton leaf curl Multan virus $(\mathrm{CLCuMuV})$ for degradation [24], and CLCuMuV $\beta C 1$ protein induces autophagy by disrupting the interaction of autophagy-related gene 3 (ATG3) with glyceraldehyde-3phosphate dehydrogenases [25].

During RNA virus infection in plant, autophagy also has an antiviral function. For example, infection of turnip mosaic virus (TuMV) in Arabidopsis thaliana and Nicotiana benthamiana plants can be inhibited by the NBR1-dependent selective autophagy [26]. In addition, the core autophagic protein Beclin1 has been shown to interact with TuMV nuclear inclusion body $b$ protein (NIb), inhibit its polymerase activity, and recruit this viral protein into autophagosomes for degradation through an interaction with ATG8a [27]. Concomitantly, plant viruses can also manipulate autophagy to fend off plant defense. For example, barley stripe mosaic virus (BSMV) $\gamma \mathrm{b}$ protein can impair ATG7-ATG8 interaction to disturb autophagy-mediated antiviral defense [28]. Therefore, we consider that the arm race between virus and plant autophagy can dramatically affect plant defense against virus infection. To date, no study on the interaction between PMMoV and its host autophagy has been published.

In the present study, we investigated the global changes of gene expressions during PMMoV infection in pepper using an RNA-seq technology, and demonstrated an antiviral role of autophagy in plant responses to PMMoV infection. Our results provide new insights into the global view of RNA transcriptions after PMMoV infection in pepper and the anti-PMMoV role of host autophagy. 


\section{Results}

Disease symptoms in PMMoV-infected pepper plants

Pepper seedlings were inoculated with PMMoV-HLD isolate. Compared with the Mock-inoculated control plants, the PMMoV-inoculated pepper plants showed foliar chlorosis and distortion by 9 days post inoculation (dpi) (Fig. 1a). Infection of PMMoV in the symptomatic plants was confirmed by reverse transcriptionpolymerase chain reaction (RT-PCR) using PMMoV CP gene specific primers (Fig. 1b).

\section{RNA-seq analysis}

To explore the global gene expression changes in pepper plants upon PMMoV infection, we constructed six libraries from three PMMoV-infected and three Mockinoculated control pepper leaf samples, and analyzed them through RNA-seq. A total of $81.38 \mathrm{~GB}$ raw reads were obtained from these libraries (i.e., 89,803,414; 92, 455,590 and 86,583,222 clean reads from three PMMoVinfected libraries, and 93,118,712; 95,261,864 and 87,522, 578 clean reads from three Mock-inoculated libraries, Table 1). Among these reads, the percentage of reads mapped to the pepper genome was over $82.33 \%$
(PMMoV-infected libraries) and 83.28\% (Mock-inoculated libraries), respectively (Table 1). For each library, more than $94.20 \%$ of the clean reads had a mass score at Q30 (0.1\% error probability of basic calls). Furthermore, the GC content of the obtained reads ranged from 43.57 to $44.07 \%$ (Table 1 ).

\section{Identification of Differentially Expressed Genes (DEGs) in the PMMoV-infected pepper plants}

To identify genes that play important roles during PMMoV infection in pepper plants, we analyzed the transcriptomic profiles of these six libraries and presented the expression level of each gene as FPKM, (Additional file 1). A total of 197 DEGs were identified in the PMMoVinfected libraries using the significance criteria of FDR < 0.05 and $\left|\log _{2}(\mathrm{FC})\right| \geq 1$. These DEGs included 172 upregulated and 25 down-regulated genes (Fig. 1c, d and Additional file 1). An overview of the transcriptomic profiles and hierarchical clustering is illustrated (Fig. 1e).

\section{Functional enrichment analysis of DEGs}

To elucidate the main functions of DEGs, Gene Ontology (GO) analysis was performed (Additional file 2). The

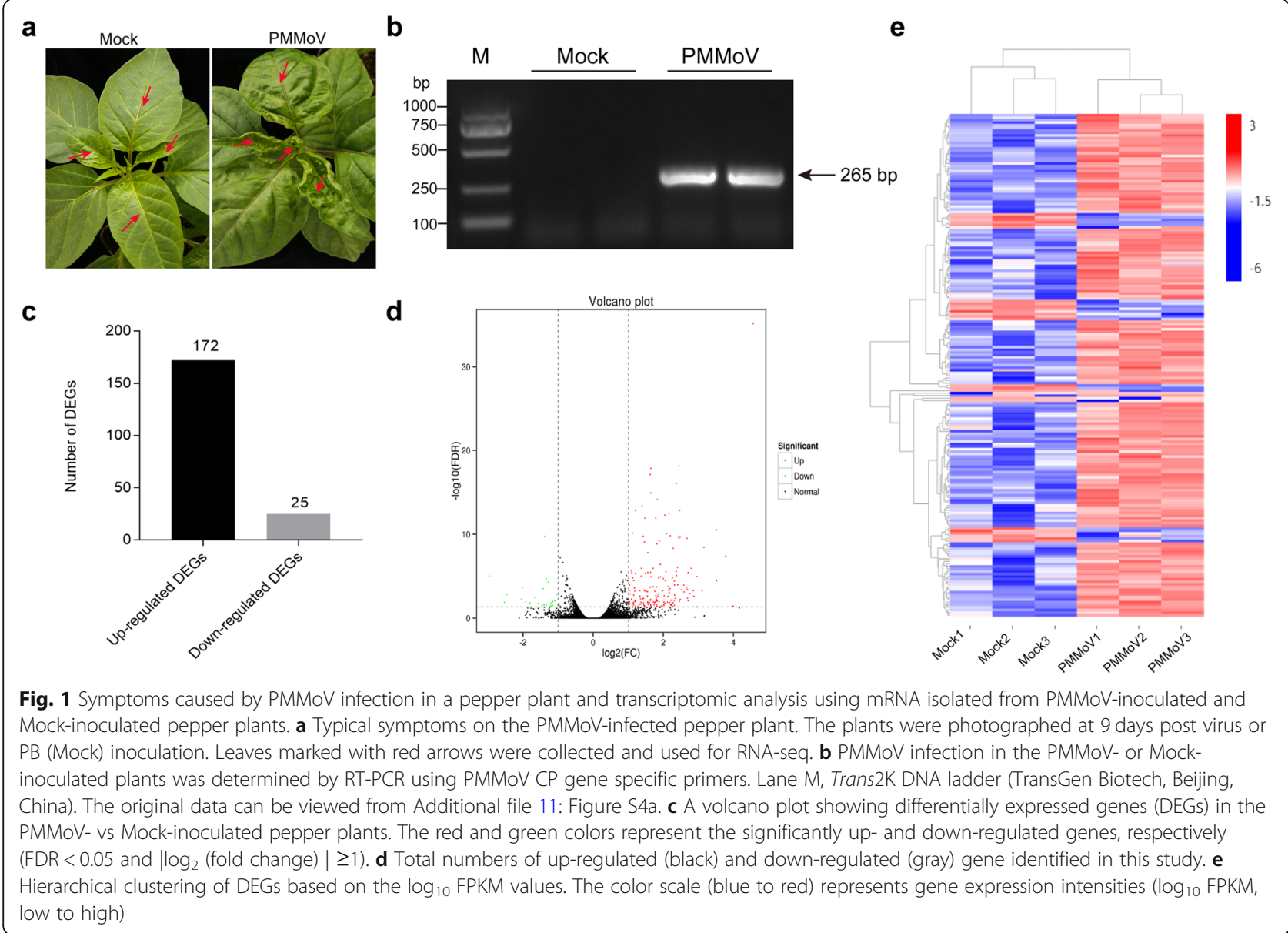


Table 1 Summary of RNA-seq data

\begin{tabular}{lllllll}
\hline Reads & Sample & & & & \\
\cline { 2 - 7 } & Mock-1 & Mock-2 & Mock-3 & PMMoV-1 & PMMoV-2 & PMMoV-3 \\
\hline Clean Reads & $93,118,712$ & $95,261,864$ & $87,522,578$ & $89,803,414$ & $92,455,590$ & $86,583,222$ \\
Mapped Reads & $77,549,891$ & $79,662,354$ & $73,466,998$ & $75,027,543$ & $76,114,634$ & $71,325,528$ \\
& $83.28 \%$ & $83.62 \%$ & $83.94 \%$ & $83.55 \%$ & $82.33 \%$ & $82.38 \%$ \\
Unique Mapped Reads & $71,992,503$ & $74,000,161$ & $67,056,890$ & $69,971,154$ & $69,015,728$ & $66,366,868$ \\
& $77.31 \%$ & $77.68 \%$ & $76.62 \%$ & $77.92 \%$ & $74.65 \%$ & $76.65 \%$ \\
Multiple Map Reads & $5,557,388$ & $5,662,193$ & $6,410,108$ & $5,056,389$ & $7,098,906$ & $4,958,660$ \\
& $5.97 \%$ & $5.94 \%$ & $7.32 \%$ & $5.63 \%$ & $7.68 \%$ & $5.73 \%$ \\
GC Contents & $43.85 \%$ & $43.59 \%$ & $43.90 \%$ & $43.57 \%$ & $44.07 \%$ & $43.67 \%$ \\
Q30 & $95.08 \%$ & $94.93 \%$ & $94.84 \%$ & $94.75 \%$ & $94.60 \%$ & $94.20 \%$ \\
\hline
\end{tabular}

most significant GO terms were then used to cluster the functions of DEGs, and the GO terms $(F D R<0.05)$ in the three main categories were presented (Fig. 2a). Based on this result, most of the enriched GO terms in the biological process category were involved in responses to abiotic and biotic stresses (Fig. 2a and Additional file 2). In the cellular component category, the membrane and chloroplast associated GO terms were the most dominant terms. In the molecular function category, the GO term with protein kinase activity was enriched (Fig. 2a and Additional file 2).

To further dissect the molecular and biological functions of DEGs, the Kyoto Encyclopedia of Genes and Genomes (KEGG) database was used. Our results showed that the DEGs were clustered in 61 KEGG pathways (Additional file 3). Among them, six pathways were significantly enriched, with $p$-value $<0.05$ (Fig. $2 \mathrm{~b}$ and Additional file 4). The significantly enriched DEGs are those involved in the 'stilbenoid, diarylheptanoid and gingerol biosynthesis' (ko00945); 'phenylpropanoid biosynthesis' (ko00940); 'cutin, suberine and wax biosynthesis' (ko00073); 'flavonoid biosynthesis' (ko000941); 'phenylalanine metabolism' (ko00360); and 'biosynthesis of unsaturated fatty acids' (ko01040). Through the enrichment analysis of KEGG pathways, most DEGs were found to be related to the secondary metabolite biosynthesis and amino acid metabolism. This finding further indicated that $\mathrm{PMMoV}$ infection in pepper plants could significantly activate or deactivate the expressions of genes involved in various secondary metabolism pathways. We speculate that the secondary metabolites produced through these pathways might act to enhance plant responses to various stress conditions (Additional file 4).

\section{Validation of RNA-seq data}

To validate the RNA-seq results, 12 DEGs related to plant defense responses were selected and tested for their expressions through RT-qPCR. These analyzed genes were: E3 ubiquitin-protein ligase PUB24 (CaPUB24), disease resistance protein RPP13 (CaRPP13), WRKY transcription factor 50 (CaWRKY50), RING-H2 finger protein ATL4O (CaATL40), plastid-lipid-associated protein 11 (CaPAP11), UDP-glucose 6-dehydrogenase 3 (CaUGD13), pectinesterase inhibitor 20 (CaPEI20), Gtype lectin S-receptor-like serine/threonine-protein kinase RLK1 (CaRLK1), pathogenesis-related protein STH-2 (CaSTH2), U-box domain-containing protein 21 (CaUB21), serine carboxypeptidase II-3 (CaSCP3) and $L R R$ receptor-like serine/threonine-protein kinase GSO1 (CaGSO1). The results showed that the expressions of CaPUB24, CaRPP13, CaWRKY50, CaATL40, CaRLK1, CaSTH2, CaUB21 and CaGSO1 were indeed induced upon PMMoV infection, while the expressions of CaPAP11, CaUGD3, CaPEI20 and CaSCP3 were downregulated, consistent with the transcriptomic data (Fig. 2c and Additional file 1).

\section{PMMoV infection can induce autophagy in $\mathbf{N}$. benthamiana plants}

The above RNA-seq results have also indicated that the accumulations of several ATGs were up-regulated upon PMMoV infection (Additional file 5). This finding encouraged us to investigate whether autophagy was involved in defense responses to PMMoV infection. In this study, we selected PMMoV and $N$. benthamiana, a systemic host of PMMoV, as our test model. Our initial virus inoculation and RT-qPCR assays showed that the expressions of NbATG3, NbATG5, NbBeclin1, NbATG8a and NbATG8f in the PMMoV-inoculated N. benthamiana leaves were significantly up-regulated at $5 \mathrm{dpi}$ (Fig. 3a). Similar results were also found in the systemic leaves of the PMMoV-inoculated N. benthamiana plants at $10 \mathrm{dpi}$ (Fig. 3b). We then analyzed the effect of PMMoV infection on autophagy through transient expression of a GFP:NbATG8a fusion protein in the PMMoV-infected or non-infected $N$. benthamiana leaves. Compared with the non-infected $N$. benthamiana 


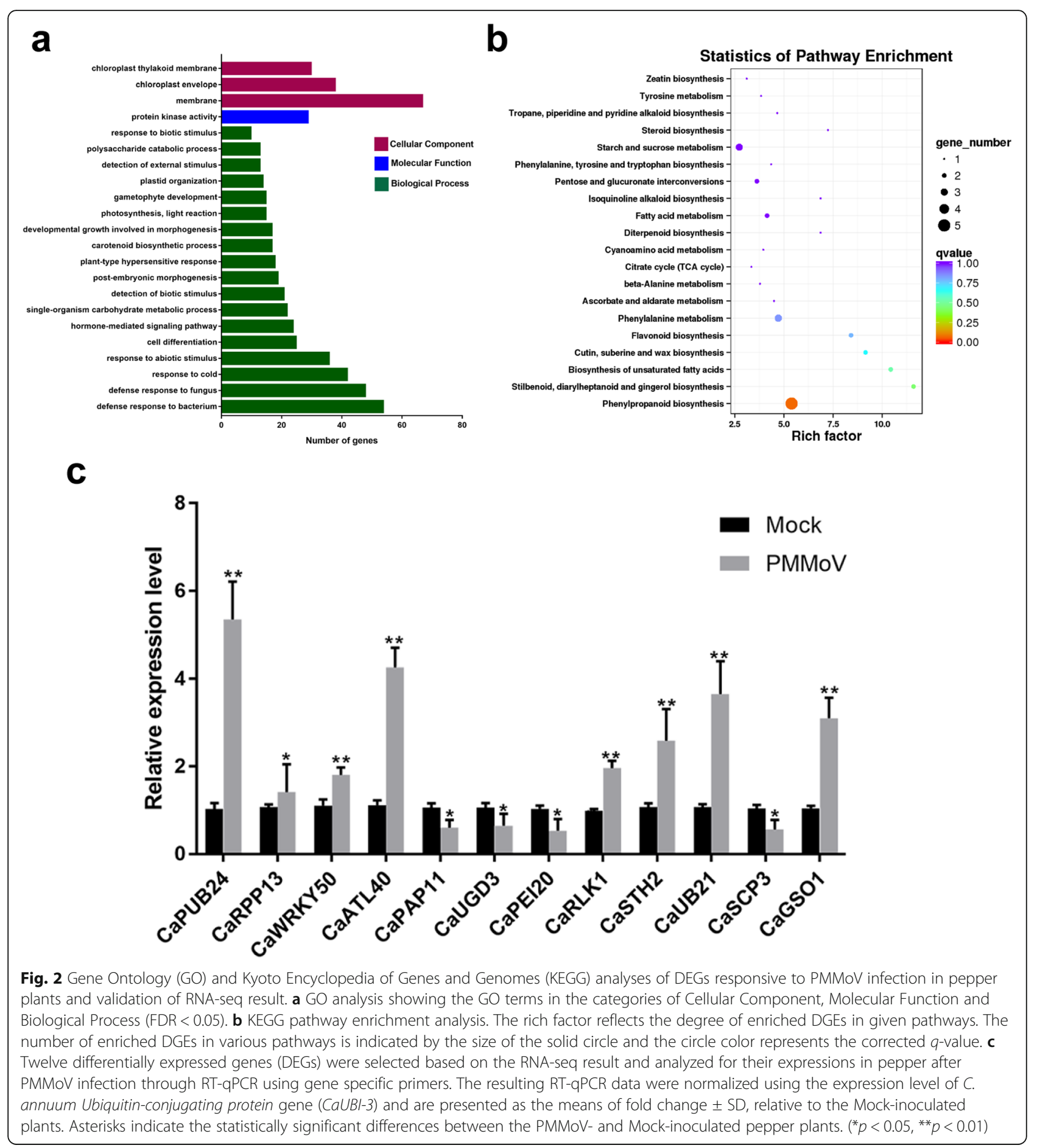

leaves, the number of green fluorescent punctate, resembling the pre-autophagosomal or autophagosomal structures, was increased by more than two-fold in the PMMoV-infected $N$. benthamiana leaves (Fig. 3c, d). Consistently, high levels of ATG8 proteins were detected in PMMoV-infected $N$. benthamiana plants by immunoblotting. The conversion of ATG8 to ATG8-PE is generally considered to be a reliable indicator of autophagy. At 5 and 10 dpi, the accumulation level of ATG8$\mathrm{PE}$ was increased notably in PMMoV-infected $N$. benthamiana plants by immunoblot assays (Fig. 3e). Transmission electron microscopy (TEM) results showed that PMMoV infection in $N$. benthamiana plants induced numerous autophagic structures in leaf 


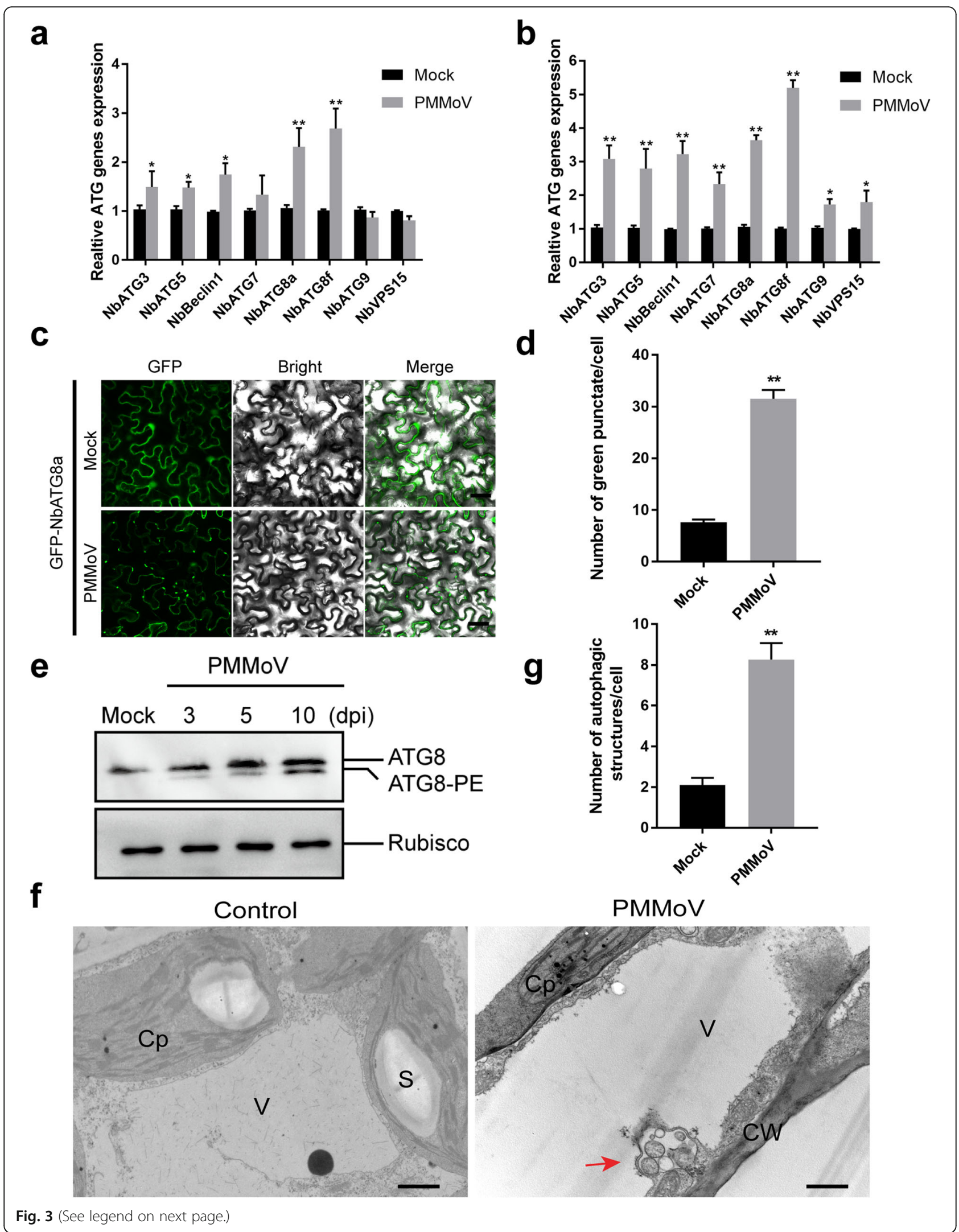




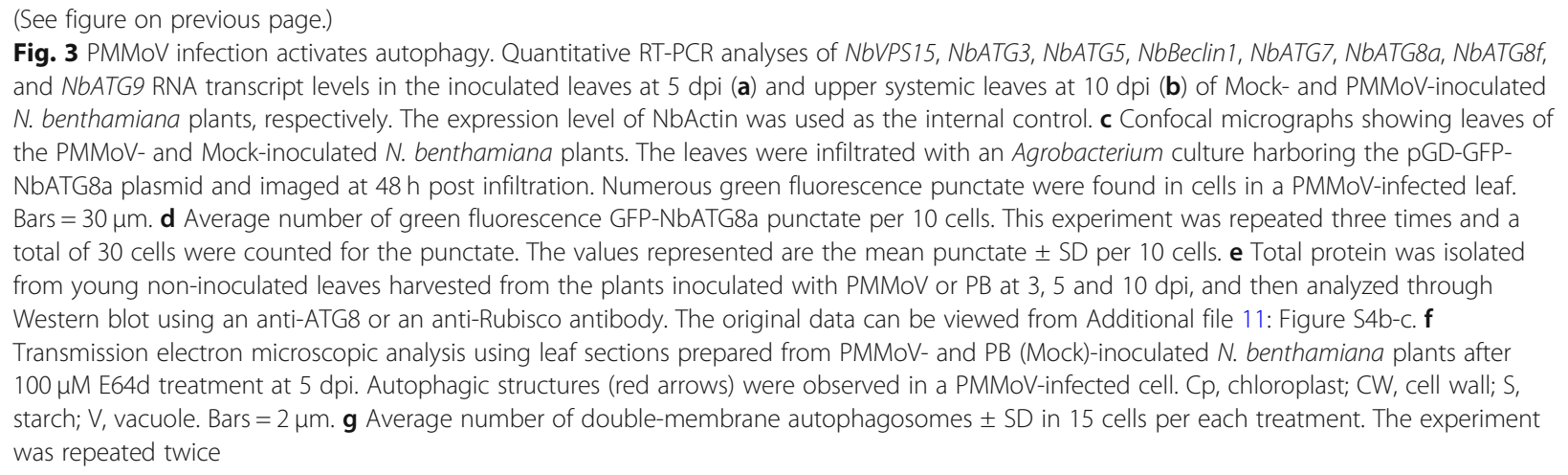

cells, compared with the non-infected $N$. benthamiana leaf cells (Fig. 3f, g). Taken together, these results demonstrated that PMMoV infection can induce autophagy in $N$. benthamiana plants.

\section{Inhibition of autophagy can increase PMMoV RNA accumulation in $\mathrm{N}$. benthamiana}

To investigate the role of autophagy in PMMoV infection, $N$. benthamiana plants were first inoculated with PMMoV or with phosphate buffer only (Mock). Before sampling, the second leaf above the inoculated leaves of each assayed plant was treated with an autophagy inhibitor. At 1,3 or $5 \mathrm{dpi}$, the inhibitor-treated leaves were harvested and then analyzed for NbATG8 accumulation through Western blot assay. Leaves from the plants treated with DMSO only were used as the controls. Our results showed that after 3-MA treatment, the accumulation level of NbATG8 was significantly decreased (Fig. 4a). In contrast, the treatment with E64d significantly increased the level of NbATG8, compared with that in the DMSO-treated plant leaves (Fig. 4a). We then analyzed PMMoV RNA accumulation in the 3-MA-, E64d- or DMSO-treated plant leaves through RT-qPCR. Our results showed that the PMMoV RNA level was significantly increased in the 3-MA- or E64d-treated plants at 3 and 5 dpi (Fig. 4b), indicating that inhibition of autophagy can increase plant susceptibility to $\mathrm{PMMoV}$ infection.

\section{Knockdown of NbATG3, NbATG5, NbBeclin1, NbATG7 or NbATG8a expression promotes PMMoV infection in $N$. benthamiana}

Autophagy is known to play an antiviral role in plant [29]. To further investigate the effect of autophagy on PMMoV infection, we silenced NbATG3, NbATG5, NbBeclin1, NbATG7 and NbATG8a expressions in $N$. benthamiana plants individually using specific TRVbased VIGS vectors. Plants inoculated with the TRV vector carrying a $205 \mathrm{bp}$ GFP gene insert were used as controls. At 10 days post agroinfiltration (dpai), the third and fourth leaves above the agroinfiltrated leaves on each assayed plant were rub-inoculated with PMMoVinfected crude leaf extracts. After 7 days post PMMoV inoculation, the NbATG3-, NbATG5-, NbBeclin1-, NbATG7- or NbATG8a-silenced plants showed much stronger PMMoV symptoms on their systemic leaves than the non-silenced control plants (Fig. 5a, b). In addition, the systemic PMMoV symptoms on the genesilenced plants appeared quicker than that on the nonsilenced plants (Fig. 5c). Silencing efficiency of each target gene and PMMoV RNA accumulation were determined through RT-qPCR using the first and second systemic leaf tissues harvested from each assayed plant at 7 dpi with PMMoV, respectively (Fig. 5d and Additional file 6). The results showed that knockdown of these ATG gene expressions individually enhanced PMMoV accumulation, especially in the NbBeclin1-silenced plants (Fig. 5d), further supporting the notion that autophagy play an important anti-PMMoV infection role in plants.

\section{Discussion}

PMMoV infection is a great threat to pepper industry. Therefore, development of effective control strategies is crucial to pepper farmers. It is well known that successful virus infection in plant depends on the outcome of arm race between virus and host plant, and autophagy plays crucial roles in the arm race [30-32]. To date, how PMMoV modulates host autophagy is unclear. Since the first report of transcriptome sequencing, RNA-seq technology has been heavily and successfully used to explore host genes involved in the interactions between viruses and host plants [33-35].

Through transcriptome sequencing, we have obtained a detailed information on the changes of global gene expressions in pepper plants after PMMoV infection. Through comprehensive analysis of these RNA-seq data, we have identified 197 DEGs (Fig. 1c), associated with different regulatory pathways. We speculate that some or many DEGs, associated with host defense responses, 


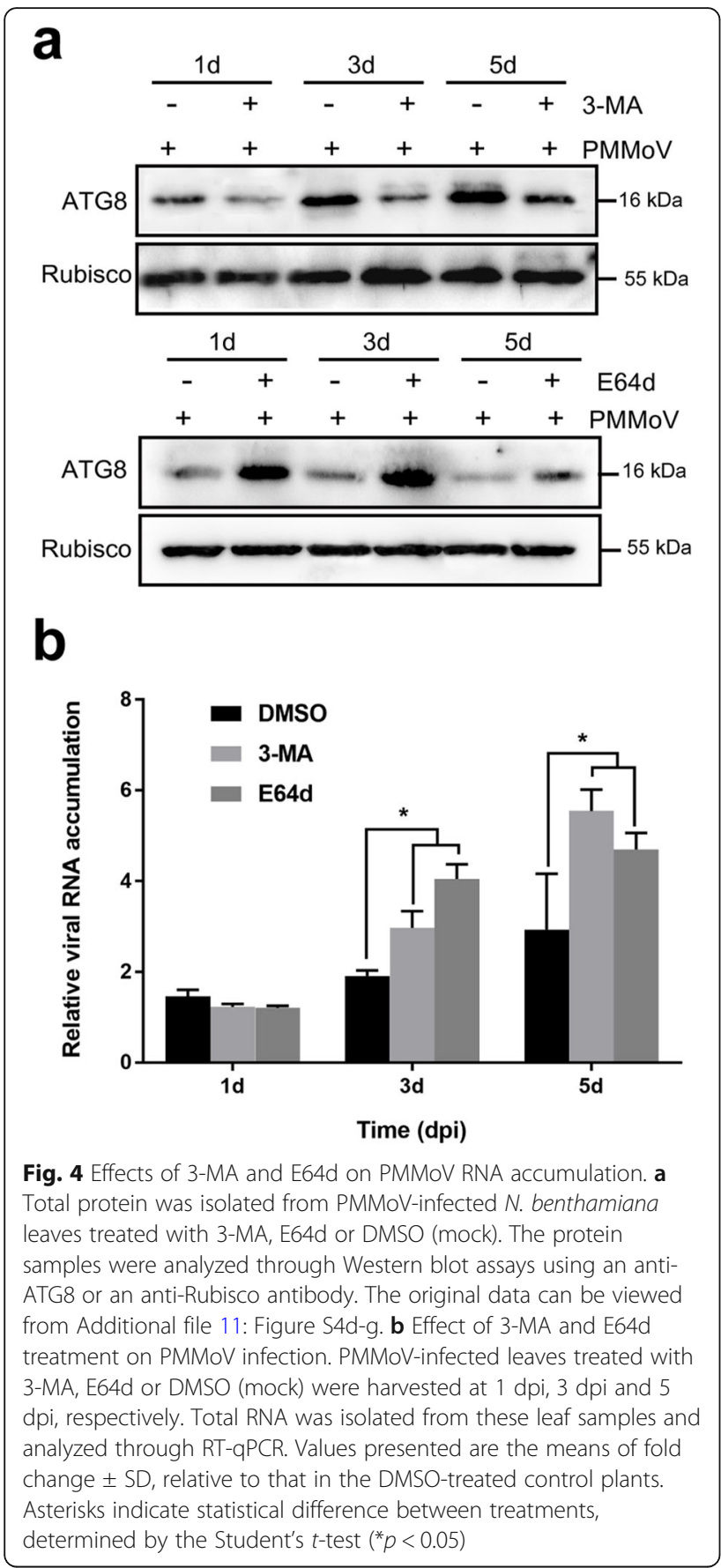

play important roles in pepper responding to $\mathrm{PMMoV}$ infection. For example, through GO and KEGG pathway analyses, multiple stress responsive genes or genes associated with plant-pathogen interaction pathways were induced upon PMMoV infection (Fig. 2). The DEG induction cascades may lead to incompatible interactions between pepper plant and PMMoV (Additional file 1), resulting in mild PMMoV symptoms (Fig. 1a). These identified DEGs are mostly associated with kinase signal transductions, transcription factors (TFs) and defense response genes. Activation of host defense responsive genes can lead to the production of antimicrobial secondary metabolites that can inhibit further spread of PMMoV in pepper plants.

Virus-induced pathogen associated molecular pattern (PAMP)-triggered immunity plays important roles in plant immunity to virus infection [32]. Plant PUB24 can act, in concert with PUB22 and PUB23, as a negative regulator of PTI in the response to several PAMPs [36]. Because the expression of CaPUB24 was induced after PMMoV infection in pepper (Fig. 2 and Additional file 1 ), we hypothesize that the induction of CaPUB24 expression may decrease PTI response and defense responses. Receptor-like protein kinases (RLKs) and receptor-like proteins (RLPs) are members of the serine/ threonine protein kinase family, and are known to be involved in sensing external signals $[37,38]$. In this study, the expression level of CaRLK1 was significantly upregulated after PMMoV infection (Fig. 2 and Additional file 1). As a receptor of pathogen signaling, leucine-rich repeat (LRR) receptor-like serine/threonine-protein kinase GSO1 was also up-regulated after PMMoV infection (Fig. 2 and Additional file 1). Pathogenesis-related (PR) proteins are well-known plant defense proteins against both biotic and/or abiotic stresses, especially pathogen infections [39]. In this work, we have found that the expressions of $P R$ genes: a tobacco mosaic virus (TMV) resistance protein gene and three disease resistance protein genes, were altered after PMMoV infection in pepper (Additional file 1). Although the expression level of $\mathrm{CaSTH} 2$ was induced upon PMMoV infection (Fig. 2 and Additional file 1), an earlier study showed that overexpression of STH2 in transgenic potato plants did not affect potato virus $\mathrm{X}$ infection [40], suggesting that CaSTH2 may not play a direct role in pepper plant against PMMoV infection. Plant disease resistance proteins can indirectly interact with specific avirulence proteins produced by pathogens. In contrast to other resistance proteins, RPP13 does not require salicylic acid accumulation, and act independently of ESD1 and NSD1 that are two independent signaling pathways that confer gene-for-gene resistance in Arabidopsis [41, 42]. In this study, the expression of CaRPP13 was up-regulated after PMMoV infection, suggesting the existence of an independent signaling pathway in response to $\mathrm{PMMoV}$ infection (Fig. 2 and Additional file 1). Many TFs have been shown to be involved in plant defense signaling pathways [43]. In this study, the expressions of seven CaWRKY genes were found to be induced after PMMoV infection (Fig. 2 and Additional file 1). Previous studies have shown that WRKY3, WRKY70 and WRKY75 are involved in plant-pathogen interactions [44, 45]. Therefore, we speculate that these seven WRKY genes may 

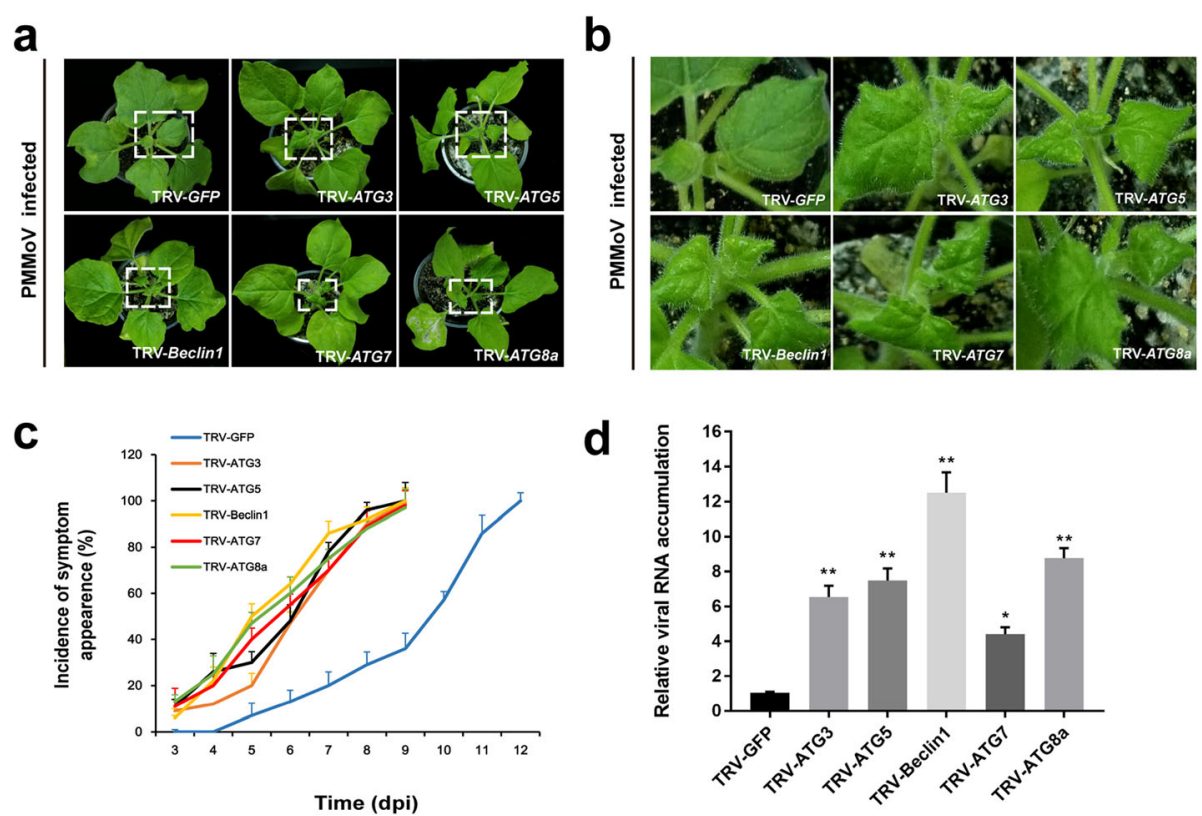

Fig. 5 Silencing of five key ATGs expressions in N. benthamiana plants through VIGS vectors enhances PMMoV infection. a Disease symptoms on the PMMoV-inoculated, NbATG3-, NbATG5-, NbBeclin1-, NbATG7- or NbATG8a-silenced N. benthamiana plants. The PMMoV-inoculated TRV-GFPinfiltrated $\mathrm{N}$. benthamiana plants were used as controls. $\mathbf{b}$ Close-up views of upper leaves indicated by white dash boxes in (a). c Percentages of PMMoV infection in various ATG-silenced plants or in the TRV-GFP-inoculated plants at various days post PMMoV inoculation. Values presented are the means \pm SD from three independent experiments. $\mathbf{d}$ Relative accumulation of PMMoV RNA in various silenced and non-silenced plants at 7 days post PMMoV inoculation. Values presented are the means \pm SD from three biological replicates. Asterisks indicate statistical difference between treatments, determined by the Student's $t$-test $\left({ }^{*} p<0.05,{ }^{* *} p<0.01\right)$

also play important roles in early pepper response to PMMoV infection.

Several recent studies on plant autophagy and pathogen infections have revealed the importance of autophagy during pathogen infections $[29,46]$. Other studies have shown the specific roles of autophagy in eliminating viruses in mammalian cells $[47,48]$. On the other hand, several plant viruses have been shown to inhibit or utilize autophagy to promote their infections in plants $[26,28,49-51]$. Here, we show that autophagy plays an important role in pepper defense responses to $\mathrm{PMMoV}$ infection. Our conclusion is based on the fact that by 9 days post PMMoV inoculation, the expressions of 17 autophagy-associated genes were altered in the pepper plants, although the expression changes of several genes were not statistically significant (Additional file 5). It is noteworthy that the RT-qPCR analysis done at $14 \mathrm{dpi}$ showed that six out of the eight analyzed autophagyassociated genes were significantly up-regulated and one was significantly down-regulated (Additional file 7), suggesting strongly that autophagy plays a role in pepper defense responses to PMMoV infection. In mammalian cells, defective ATG5 or ATG7 is unable to prevent autolysosome formations, which are known to be induced by various stresses. It is recommended that macroautophagy can occur through at least two pathways: a conventional ATG5/ATG7-dependent pathway and an atypical ATG5/ATG7-independent pathway [52]. Our results suggest that the autophagy induced by PMMoV infection is likely a conventional ATG5/ATG7dependent pathway. Several reports have indicated the involvement of ATG8 family proteins in autophagy biogenesis and cargo recruitment [53]. In this study, we further determined that silencing of NbATG3, NbATG5, NbBeclin1, NbATG7 or NbATG8a expression in $N$. benthamiana plants through VIGS vectors can enhance PMMoV RNA accumulation and disease symptom formation (Fig. 5). To explore the role of autophagy in PMMoV infection and provide a basis for further study on the relationship between autophagy and PMMoV, we analyzed the physiological significance of autophagy on PMMoV viral accumulation. By inhibiting the autophagy pathway with treatment of 3-MA or E64d, we demonstrated that PMMoV infection activated the autophagy, which was utilized by plants to inhibit PMMoV infection (Fig. 4). However, these two inhibitors had opposite effects on the accumulation of ATG8 protein (Fig. 5). 3MA can inhibit the formation of autophagosomes at the initial stage of autophagy [54], while E64d can stabilize the autophagosomes in the vacuoles to prevent its degradation at the later stage of autophagy [55], which results in a contradictive accumulation of ATG8 protein. 
In conclusion, we propose that autophagy plays an important role in plant defense responses to $\mathrm{PMMoV}$ infection (Fig. 6).

As a core component of the class III PI3K complex, Beclin1 can regulate autophagy through acting as the interaction center for different proteins [56]. Moreover, Beclin1/ATG6 complex is required during autophagy in plant, human and other eukaryotes [57]. A previous study by Liu and others has shown that silencing the expressions of Beclin1 and several other ATG genes in N. benthamiana plants through VIGS vectors enhanced TMV infection [22]. The Beclin1-mediated autophagy may also inhibit TMV infection through an interaction with TMV encoded RNA-dependent RNA polymerase (RdRp). Viral RdRp is necessary for RNA virus replication, and all the known viral RdRps have conserved GDD motifs [58]. To further explore defense responses triggered by autophagy to PMMoV infection, we investigated the interaction between the conserved GDD motif in PMMoV RdRp_2 and NbBeclin1 through a yeast two- hybrid technique. As expected, PMMoV RdRp_2 did interact with NbBeclin1 (Additional file 8), suggesting that NbBeclin1 could directly bind with PMMoV RdRp_ 2 and suppress $R d R p$ activity to restrict viral infection. Particularly, our findings further demonstrated that targeting viral $\mathrm{RdRp}$ by Beclin1 is a conserved antiviral mechanism in plants (Fig. 6). Meanwhile, our results showed that the HEL motif in PMMoV p126 could interact with NbATG8f (Additional file 8), suggesting that p126 may be a novel target for autophagic degradation by binding to NbATG8f (Fig. 6), which need to be further investigated.

\section{Conclusions}

In summary, we have analyzed pepper responses to PMMoV infection through an RNA-seq approach. Our results indicate that several genes responsible for signal transductions or stress responses may play important roles in defense responses to PMMoV infection (Fig. 6). In addition, we have shown that the expressions of many

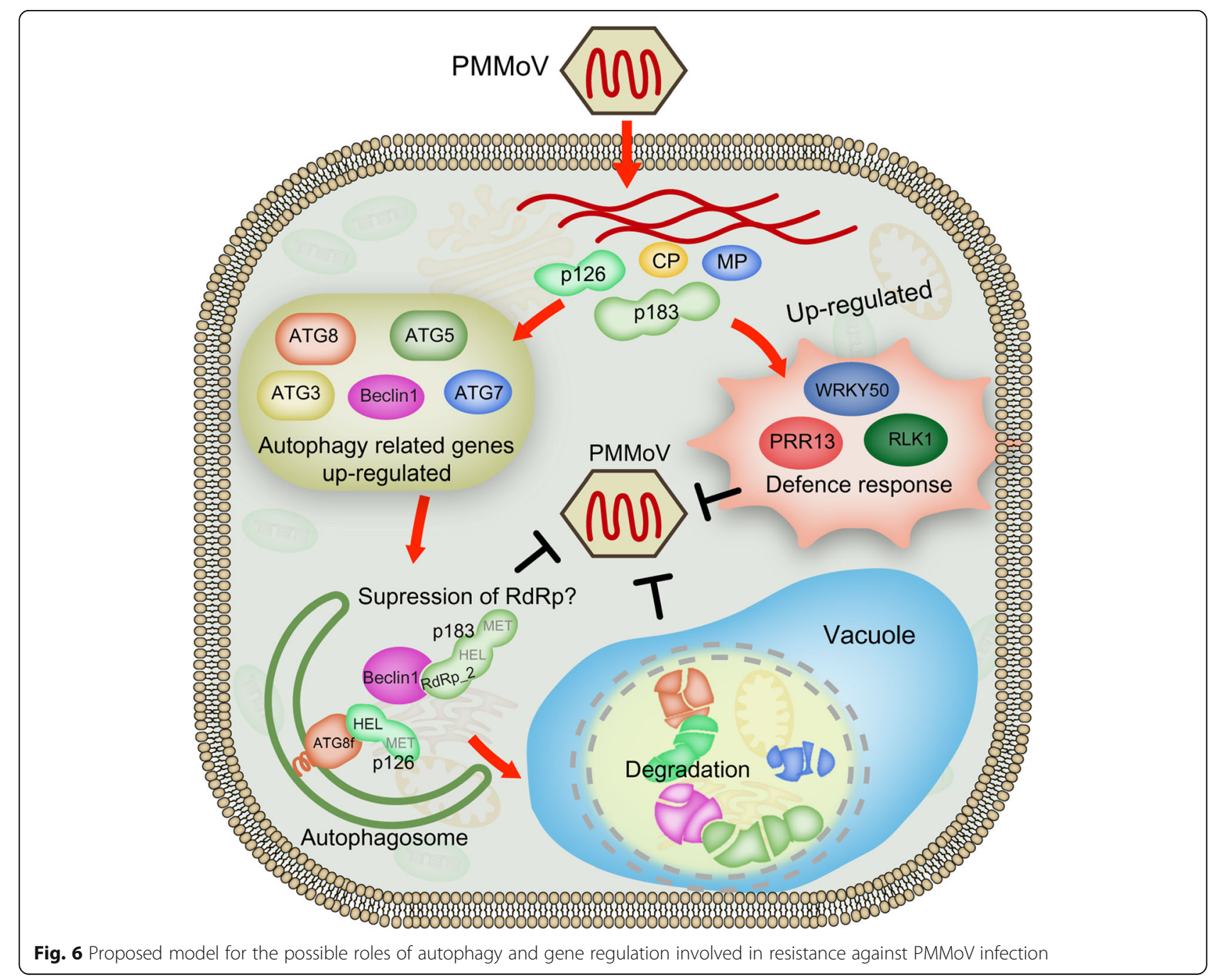


ATGs in pepper plants were up-regulated after PMMoV infection. Further studies have shown that PMMoV infection can induce autophagy in cells, and autophagy plays an antiviral role during the arm race between host plant and PMMoV (Fig. 6). These results presented in this paper should help us to better understand the mechanism controlling PMMoV infection in plant and to develop better strategies for breeding projects for virus-resistant crops.

\section{Methods}

\section{Plasmid construction}

Sequences of seven $N$. benthamiana genes: NbBeclin1 (accession number AY701316), NbVPS15 (KU561371), NbATG9 (KX369399), NbATG3 (KX369396), NbATG5 (KX369397), NbATG7 (KX369398) and NbATG8a (KX120976), were retrieved from the GenBank database (https://www.ncbi.nlm.nih.gov/genbank/). Full-length NbATG8a gene was PCR amplified and cloned behind an eGFP gene in a pGD vector to express a GFP: $\mathrm{NbATG8a}$ fusion protein. Sequences of primers used in plasmid construction are shown in Additional file 9.

\section{Plant growth and virus inoculation}

Seeds of Capsicum annuum L. cultivar 'Zunla-1' were kindly provided by Dr. Dan Xing (Guizhou Academy of Agricultural Sciences, Guiyang, China). Wild-type $N$. benthamiana seeds were propagated and stored in the Plant Virus Laboratory, Shenyang Agricultural University, Shenyang, China. All the seeds were grown inside a growth chamber set at $25^{\circ} \mathrm{C}$ and a 16 and $8 \mathrm{~h}$ (light/ dark) photoperiod and 60\% humidity. PMMoV-HLD isolate was from a previously reported source [59] in our lab. For virus inoculation, approximately $0.5 \mathrm{~g}$ of PMMoV-infected leaf tissues were homogenized in phosphate buffer $(\mathrm{PB}, 0.01 \mathrm{M}, \mathrm{pH} 7.2)$ at $1: 5(\mathrm{w} / \mathrm{v})$ ratio. The crude leaf extract was rub-inoculated to the upper two young leaves of 4-leaf stage pepper plants. At 9 days post virus inoculation (dpi), the upper un-inoculated young leaves (Fig. 1a, red arrows) were harvested, frozen in liquid nitrogen, and then stored at $-80^{\circ} \mathrm{C}$ till further use. Leaves of plants inoculated with $\mathrm{PB}$ only were also harvested at $9 \mathrm{dpi}$ and used as the non-infected controls.

\section{RNA isolation and Rreverse Transcription-Polymerase Chain Reaction (RT-PCR)}

To detect PMMoV infection in pepper plants, total RNA was extracted from collected leaf samples using the RNAiso Plus reagent (TaKaRa, Dalian, China) as instructed. Concentrations and qualities of the isolated RNA samples were monitored using a NanoDrop2000 spectrophotometer (Thermo Fisher Scientific, Waltham, USA). First-strand cDNAs were synthesized using $1 \mu \mathrm{g}$ of total RNA, an M-MLV reverse transcriptase (Promega,
Carlsbad, USA), and an equal volume of oligo (dT) and random primers $(2.5 \mu \mathrm{M})$ in a final volume of $20 \mu \mathrm{L}$ according to the manufacturer's instructions. The PCR amplification was performed in a final volume of $25 \mu \mathrm{L}$ containing 2.5 units of PrimeSTAR ${ }^{\circ}$ Max DNA polymerase (TaKaRa, Dalian, China), $1 \mu \mathrm{L}$ of each PMMoV CP gene specific primers $(10 \mu \mathrm{M})$ (Additional file 9) and $2 \mu \mathrm{L}$ of cDNA template. Conditions of PCR reaction was $35 \mathrm{cy}-$ cles of $98^{\circ} \mathrm{C}$ for $10 \mathrm{~s}, 55^{\circ} \mathrm{C}$ for $5 \mathrm{~s}$, and $72{ }^{\circ} \mathrm{C}$ for $20 \mathrm{~s}$.

\section{RNA sequencing (RNA-seq)}

For one virus inoculation experiment, the upper young leaves (Fig. 1a, red arrows) from at least 15 individual PMMoV-infected and non-infected pepper plants were pooled and used for RNA-seq, respectively. Three independent virus inoculation experiments were performed in this study. One microgram of total RNA from each sample was used as an input for RNA preparation. Sequencing libraries were constructed using the NEBNext ${ }^{\circ} \mathrm{Ultra}^{\mathrm{Tm}}$ RNA Library Prep kit (New England Biolabs, Ipswich, USA) and the NEB Next Multiplex Oligos (New England Biolabs) followed by sequencing on an Illumina HiSeq 4000 sequencing platform (Biomarker Biology Technology, Beijing, China) as instructed. Briefly, mRNA was prepared using the poly- $\mathrm{T}$ oligo-attached magnetic beads. After fragmentation, cDNAs were synthesized and then ligated with the NEB Next Adaptors with hairpin loop structures. The resulting PCR products were purified and the quality of the libraries was assessed using the Agilent Bioanalyzer 2100 system.

The clean reads were aligned individually against the reference genome of Capsicum annuum. L_Zunla-1_Release_2.0 (http://peppersequence.genomics.cn) using the TopHat 2.0 software [60]. The number of clean reads mapped to a specific gene were counted and then presented as fragments per kilobase of transcript per million mapped reads (FPKM) using Cufflinks [61]. Differentially expressed genes (DEGs) between the PMMoV-infected and the non-infected control samples (Mock) were identified using the DESeq software [62]. The DEGs were ranked individually based on the average $\log _{2}$ Fold Change (FC) and the false discovery rate (FDR) $\mathrm{Q}$ values, and then filtered using FDR Q $<0.05$ and $\left|\log _{2} \mathrm{FC}\right| \geq 1$. Gene function was annotated according to the following databases: Gene Ontology (GO), Kyoto Encyclopedia of Genes and Genomes (KEGG) Ortholog (KO), SwissProt, and NCBI non-redundant protein sequences $(\mathrm{Nr})$. GO enrichment of DEGs was determined based on the Wallenius noncentral hypergeometric distribution using the GOseq R package [63].

\section{Reverse Transcription-Quantitative PCR (RT-qPCR)}

To validate the RNA-seq results, 12 DEGs were selected and tested for their expressions through RT-qPCR. 
Three micrograms of total RNA (each sample) was used for cDNA synthesis using the HiScript III RT SuperMix kit (Vazyme, Nanjing, China) followed by qPCR amplification using the AceQ qPCR SYBR Green Master Mix kit (Vazyme) on the StepOne plus real time PCR platform (Applied Biosystems, Foster City, USA). Primers used in qPCR amplifications were designed according to the gene sequences from the Capsicum annuиm. L_Zunla-1_Release_2.0 database (http:// peppersequence.genomics.cn) and RNA-seq data. The primers were synthesized by the Sangon Biotech, Shanghai, China (Additional file 10). The expression levels of C. annuum Ubiquitin-conjugating protein gene (CaUBI3, AY486137) [64] or N. benthamiana Actin gene (NbActin, AY179605) was used as internal controls, respectively. Relative expression levels of these genes were calculated using the $2^{-\Delta \Delta C T}$ method [65]. Three biological and three technical replicates were performed for all RT-qPCR experiments.

\section{Confocal microscopy and Transmission Electron Microscopy (TEM)}

Fully expanded leaves of 3-week-old $N$. benthamiana plants were rub-inoculated with PMMoV-infected crude leaf extract. After $5 \mathrm{dpi}$, the second leaf above the inoculated leaves was infiltrated with Agrobacterium tumefaciens strain GV3101 $\left(\mathrm{OD}_{600}=0.6\right)$ containing the recombinant pGD vector expressing GFP:NbATG8a fusion. At $48 \mathrm{~h}$ post agroinfiltration (hpai), the infiltrated leaf areas were sampled and examined under an Olympus Fluoview FV3000 confocal laser scanning microscope (Olympus, Tokyo, Japan). The excitation wavelength was set at $488 \mathrm{~nm}$ and the emission was captured at $522 \mathrm{~nm}$.

At $5 \mathrm{dpi}$, a systemic leaf of the PMMoV- or Mockinoculated $N$. benthamiana plants was treated with $100 \mu \mathrm{M}$ E64d diluted in a DMSO solution or with DMSO solution alone (mock) for $10 \mathrm{~h}$. The treated leaves were then harvested and cut into small segments $\left(1-2 \mathrm{~mm}^{2}\right)$ for electron microscopic analysis. The tissue fixation, embedding, sectioning and TEM observation were as described [66].

\section{Chemical treatments}

Autophagy inhibitors 3-methyladenine (3-MA; Sigma, Darmstadt, Germany) and E64d (Abcam, Eugene, USA) were used to investigate the effects of autophagy on PMMoV infection. 3-MA disturbs early autophagosome formation due to the suppression of class III PtdIns 3kinase, and E64d can stabilize autophagic bodies in the vacuole to inhibit autophagy at late stage $[54,55]$. Infiltration buffer containing dimethyl sulfoxide (DMSO; Mock) or an equal volume of DMSO with $5 \mathrm{mM} 3-\mathrm{MA}$, or $100 \mu \mathrm{M}$ E64d for inhibition of autophagy, was infiltrated into leaves for $10 \mathrm{~h}$ before samples were collected.

\section{Western blot analysis}

Total protein was extracted from agroinfiltrated leaves as described previously [67]. Concentrations of total protein in different samples were quantified using the bicinchoninic acid (BCA) method followed by electrophoresis in 10\% SDS-PAGE gels. For ATG8 detection, the denatured proteins were separated on a $15 \%$ SDSPAGE gel in the presence of $6 \mathrm{M}$ urea. For western blotting, the separated protein bands were transferred onto $0.45 \mu \mathrm{m}$ polyvinylidene fluoride (PVDF) membranes (Millipore, Billercia, USA). Then, the membranes were blocked with a $5 \%$ Difco $^{\text {тm }}$ skim milk (Becton Dickinson and Company, Sparks, USA) solution and then probed overnight with an antibody specific for ATG8 (Agrisera, Vännäs, Sweden) or Rubisco (Abbkine, California, USA) at $4{ }^{\circ} \mathrm{C}$. After several rinses in the Trisbuffered saline supplemented with $0.1 \%$ Tween 20 (TBST), the membranes were incubated again in a horseradish peroxidase (HRP)-conjugated goat antirabbit IgG solution (ZSGB-BIO, Beijing, China) for $1 \mathrm{~h}$ at room temperature. After several rinses in the TBST buffer, the detection signal was visualized by incubating the membranes in a chemiluminescent detection reagent kit as instructed (Millipore).

\section{Virus-Induced Gene Silencing (VIGS) assay}

For VIGS assays, fragments representing partial sequence of NbBeclin1 (343 bp), NbATG8a (265 bp), NbATG3 (329 bp), NbATG5 (317 bp) or NbATG7 (324 bp) were RT-PCR-amplified and inserted individually into a Tobacco rattle virus (TRV)-based VIGS vector. Briefly, these fragments were amplified individually from an $N$. benthamiana cDNA through PCR using specific primers (Additional file 10) and the PrimeSTAR ${ }^{\circ}$ Max DNA Polymerase (TaKaRa). The resulting PCR fragments were digested with the $\mathrm{BamH}$ I and Xho I restriction enzymes and cloned individually into the pTRV2 plasmid to produce pTRV2-Beclin1, pTRV2-NbATG8a, pTRV2-NbATG3, pTRV2-NbATG5 and pTRV2NbATG7, respectively. These new plasmids and the pTRV1 plasmid were transformed individually into Agrobacterium tumefaciens strain GV3101 cells. After propagation, each Agrobacterium culture was pelleted and then resuspended in an infiltration buffer containing $10 \mathrm{mM}$ MES, $10 \mathrm{mM} \mathrm{MgCl}_{2}$, pH 7.2, and $150 \mu \mathrm{M}$ Acetosyringone. Agrobacterium culture harboring pTRV1 was mixed with an equal amount of Agrobacterium culture harboring pTRV2-Beclin1, pTRV2-NbATG8a, pTRV2NbATG3, pTRV2-NbATG5 or pTRV2-NbATG7. The mixed cultures were referred to as TRV-NbATG3, TRVNbATG5, TRV-NbATG7, TRV-NbATG8a, and TRV2- 
Beclin1, respectively. The final optical density $\left(\mathrm{OD}_{600}\right)$ of each mixed Agrobacterium culture was 0.5, and the cultures were infiltrated individually into leaves of 4-5 leaf stage $N$. benthamiana plants using needleless syringes. At 10 days post agroinfiltration (dpai), the upper noninfiltrated $N$. benthamiana leaves were inoculated with PMMoV-infected crude $N$. benthamiana leaf extracts or PB only (Mock).

\section{Supplementary Information}

Supplementary information accompanies this paper at https://doi.org/10. 1186/s12870-020-02711-X.

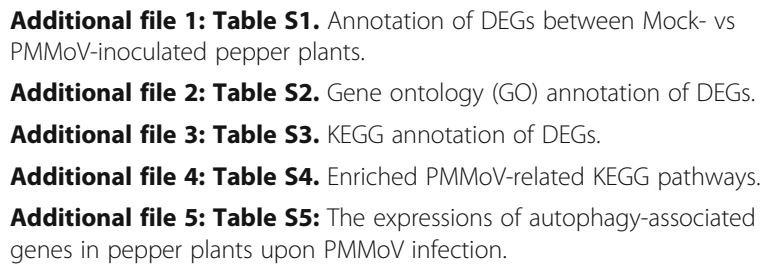

Additional file 2: Table S2. Gene ontology (GO) annotation of DEGs. Additional file 3: Table S3. KEGG annotation of DEGs. Additional file 4: Table S4. Enriched PMMoV-related KEGG pathways. Additional file 5: Table S5: The expressions of autophagy-associated genes in pepper plants upon PMMoV infection.

Additional file 6: Figure S1. Silencing efficiency of five ATGS in N. benthamiana plants through VIGS vectors.

Additional file 7: Figure S2. Relative expressions of eight ATGs in pepper plants infected with PMMoV.

Additional file 8: Figure S3. Analysis of interaction between PMMoV viral proteins and autophagy proteins through yeast two hybrid assay.

Additional file 9: Table S6. Primers used for PMMoV detection and vector construction.

Additional file 10: Table S7. Primers used for RT-qPCR in this study. Additional file 11: Figure S4. Source data for Fig. 1b, Fig. 5e and Fig. 6a. (a) Red frame displayed the source data for Fig. 1b. (b-c) Full scan of results shown in Fig. 5e. (d-g) Full scan of the results shown in Fig. 6a.

\section{Abbreviations}

ATG: Autophagy-related gene; BSMV: Barley stripe mosaic virus; CaMv: Cauliflower mosaic virus; CLCuMuV: Cotton leaf curl Multan virus; DEG: Differentially expressed gene; DMSO: Dimethyl sulfoxide; Dpai: Days post agroinfiltration; FPKM: Fragments per kilobase of transcript per million mapped reads; Hpai: Hours post agroinfiltration; PCD: Programmed cell death; PMMoV: Pepper mild mottle virus; PVDF: Polyvinylidene fluoride; RdRp: RNA-dependent RNA polymerase; TEM: Transmission electron microscopy; TMV: Tobacco mosaic virus; TRV: Tobacco rattle virus; TuMV: Turnip mosaic virus

\section{Acknowledgements}

We thank Dr. Andrew O. Jackson (Department of Plant and Microbial Biology, University of California, Berkeley, USA) for providing the vector pGD, and Dr. Yule Liu (School of Life Sciences, Tsinghua University, Beijing, China) for providing the VIGS vectors pTRV1 and pTRV2.

\section{Authors' contributions}

$Y J$ and MA performed the experiments. $Z X$ and $Y W$ participated in experimental design and coordination. $X L, M Y$ and $Y J$ collected the samples. YJ and MA drafted the manuscript. MA, XZ, ZX and YW proofread and finalized the manuscript. All authors have read and approved the final manuscript.

\section{Funding}

This research was funded by National Key R\&D Program of China (2016YFD0201004), and High-tech R\&D Program of Liaoning (2019JH2/ 10200012). These funding bodies had no role in the design of the study; in collection, analysis, or interpretation of data; in writing the manuscript.

\section{Availability of data and materials}

The raw data collected from RNA-seq was availability in national center for biotechnology information (NCBI): https://dataview.ncbi.nlm.nih.gov/objects?linked_to_id=PRJNA631504\&archive=biosample. SRA accession: PRJNA631504. The datasets used and/or analysed during the current study are available from the corresponding author on reasonable request.

Ethics approval and consent to participate

Not applicable.

\section{Consent for publication}

Not applicable.

\section{Competing interests}

The authors declare that there is no conflict of interest regarding the publication of this paper.

\section{Author details}

${ }^{1}$ College of Plant Protection, Shenyang Agricultural University, Shenyang 110866, China. ${ }^{2}$ General Station of Forest and Grassland Pest and Diseases Control, National Forestry and Grassland Administration, Shenyang 110034, China.

Received: 13 May 2020 Accepted: 20 October 2020

Published online: 29 October 2020

\section{References}

1. Kim MS, Kim S, Jeon J, Kim KT, Lee HA, Lee HY, Park J, Seo E, Kim SB, Yeom $\mathrm{SI}$, Lee $\mathrm{YH}$, Choi D. Global gene expression profiling for fruit organs and pathogen infections in the pepper, Capsicum annuum L. Sci Data. 2018;5: 180103.

2. Peng J, Shi B, Zheng H, Lu Y, Lin L, Jiang T, Chen J, Yan F. Detection of pepper mild mottle virus in pepper sauce in China. Arch Virol. 2015;160: 2079-82.

3. Lockhart BEL, Fischer HU. Serious losses caused by potato virus $Y$ infection in peppers in Morocco. Plant Dis Rep. 1974;58:141-3.

4. Wetter C, Conti M, Altschuh D, Tabillion R, Regenmortel MHV. Pepper mild mottle virus, a tobamovirus infecting pepper cultivar in Sicily. Phytopathology. 1984;74:405-10.

5. Ikegashira Y, Ohki T, Ichiki UT, Higashi T, Hagiwara K, Omura T, Honda Y, Tsuda S. An immunological system for the detection of Pepper mild mottle virus in soil from green pepper fields. Plant Dis. 2004;88:650-6.

6. Adams MJ, Antoniw JF, Kreuze J. Virgaviridae: a new family of rod-shaped plant viruses. Arch Virol. 2009;154:1967-72.

7. King AMQ, Lefkowitz E, Adams MJ, Carstens EB. Virus taxonomy: Ninth report of the International Committee on Taxonomy of Viruses. Amsterdam: Elsevier Academic Press; 2011.

8. Kim JS, Lee SH, Choi HS, Kim MK, Kwak HR, Kim JS, Nam M, Cho JD, Cho IS, Choi GS. Characteristics of plant virus infections on crop samples submitted from agricultural places. Res Plant Dis. 2012;18:277-89.

9. Colson P, Richet H, Desnues C, Balique F, Moal V, Grob JJ, Berbis P, Lecoq H, Harlé JR, Berland Y, Raoult D. Pepper mild mottle virus, a plant virus associated with specific immune responses, fever, abdominal pains, and pruritus in humans. PLoS One. 2010;5:1-12.

10. Whitham SA, Yang C, Goodin MM. Global impact: elucidating plant responses to viral infection. Mol Plant-Microbe Interact. 2006;19:1207-15.

11. Rubiales D, Fondevilla S, Chen W, Gentzbittel L, Higgins TJV, Castillejo MA, Singh KB, Rispail N. Achievements and challenges in legume breeding for pest and disease resistance. Crit Rev Plant Sci. 2015;34:195-236.

12. Lu J, Du ZX, Kong J, Chen LN, Qiu YH, Li GF, Meng XH, Zhu SF. Transcriptome analysis of Nicotiana tabacum infected by Cucumber mosaic virus during systemic symptom development. PLoS One. 2012;7:e43447.

13. Pacheco R, Garcia-Marcos A, Manzano A, Garcia LM, Camanes G, GarciaAgustin P, Ramon DJ, Tenllado F. Comparative analysis of transcriptomic and hormonal responses to compatible and incompatible plant-virus interactions that lead to cell death. Mol Plant-Microbe Interact. 2012;25: 709-23.

14. Miozzi L, Napoli C, Sardo L, Accotto GP. Transcriptomics of the interaction between the monopartite phloem-limited geminivirus tomato yellow leaf curl Sardinia virus and Solanum lycopersicum highlights a role for plant 
hormones, autophagy and plant immune system fine tuning during infection. PLoS One. 2014;9:e89951.

15. Tian XR, Li SD, Liu YS, Liu XM. Transcriptomic profiling reveals metabolic and regulatory pathways in the desiccation tolerance of mungbean (Vigna radiata [L.] R. Wilczek). Front Plant Sci. 2016;7:1921.

16. Kim KT, Jung K, Lee GW, Oh SK, Bae C, Kim SB, Lee HY, Kim SY, Kim IY, Choi BS, Lim JS, Lee YH, Choi D, et al. Genome sequence of the hot pepper provides insights into the evolution of pungency in Capsicum species. Nat Genet. 2014;46:270-8.

17. Qin C, Yu CS, Shen Y, Fang XD, Chen L, Min JM, Cheng JW, Zhao SC, Xu M, Luo $Y$, et al. Whole-genome sequencing of cultivated and wild peppers provides insights into Capsium domestication and specialization. Proc Natl Acad Sci U S A. 2014;14:5135-40.

18. Boya P, Reggiori F, Codogno P. Emerging regulation and functions of autophagy. Nat Cell Biol. 2013;15:713-20.

19. Üstün S, Hafrén A, Hofius D. Autophagy as a mediator of life and death in plants. Curr Opin Plant Biol. 2017:40:122-30.

20. Doherty J, Baehrecke EH. Life, death and autophagy. Nat Cell Biol. 2018;20: $1110-7$.

21. Han $S, Y u B$, Wang Y, Liu Y. Role of plant autophagy in stress response. Protein Cell. 2011;2:784-91.

22. Liu Y, Schiff M, Czymmek K, Tallóczy Z, Levine B, Dinesh-Kumar SP. Autophagy regulates programmed cell death during the plant innate immune response. Cell. 2005;121:567-77.

23. Hafrén A, Macia IL, Love AJ, Milner JJ, Drucker M, Hofius D. Selective autophagy limits cauliflower mosaic virus infection by NBR1-mediated targeting of viral capsid protein and particles. Proc Natl Acad Sci U S A. 2017;114:2026-35.

24. Haxim $Y$, Ismayil A, Jia Q, Wang $Y$, Zheng $X$, Chen T, Qian L, Liu N, Wang $Y$, Han S, Cheng J, Qi Y, Hong Y, Liu Y. Autophagy functions as an antiviral mechanism against geminiviruses in plants. eLife. 2017;6:e23897.

25. Ismayil A, Yang M, Haxim Y, Wang $Y$, Li J, Han L, Wang Y, Zheng $X$, Wei $X$ Nagalakshmi U, Hong Y, Hanley-Bowdoin L, Liu Y. Cotton leaf curl Multan virus $B C 1$ protein induces autophagy by disrupting the interaction of autophagy-related protein 3 with glyceraldehyde-3-phosphate dehydrogenases. Plant Cell. 2020;32:1124-35.

26. Hafrén A, Üstün S, Hochmuth A, Svenning S, Johansen T, Hofius D. Turnip mosaic virus counteracts selective autophagy of the viral silencing suppressor HC-pro. Plant Physiol. 2018;176:649-62.

27. Li F, Zhang C, Li Y, Wu G, Hou X, Zhou X, Wang A. Beclin1 restricts RNA virus infection in plants through suppression and degradation of the viral polymerase. Nat Commun. 2018;9:e1268.

28. Yang M, Zhang Y, Xie X, Yue N, Li J, Wang X, Han C, Yu J, Liu Y, Li D. Barley stripe mosaic virus $\gamma b$ protein subverts autophagy to promote viral infection by disrupting the ATG7-ATG8 interaction. Plant Cell. 2018;30:1582-95.

29. Kushwaha NK, Hafrén A, Hofius D. Autophagy-virus interplay in plants: from antiviral recognition to proviral manipulation. Mol Plant Pathol. 2019;20:1211-6.

30. Clavel M, Michaeli S, Genschik P. Autophagy: a double-edged sword to fight plant viruses. Trends Plant Sci. 2017;22:646-8.

31. Hofius D, Schultz-Larsen T, Joensen J, Tsitsigiannis DI, Petersen NH, Mattsson $\mathrm{O}$, Jørgensen LB, Jones JDG, Mundy J, Petersen M. Autophagic components contribute to hypersensitive cell death in Arabidopsis. Cell. 2009;137:773-83.

32. Wu X, Valli A, Garcia JA, Zhou X, Cheng X. The tug-of-war between plants and viruses: great progress and many remaining questions. Viruses. 2019:11:e203.

33. Li K, Wu GT, Li MJ, Ma MG, Du J, Sun M, Sun XC, Qing L. Transcriptome analysis of Nicotiana benthamiana infected by Tobacco curly shoot virus. Virol J. 2018;15:138.

34. Rubio M, Rodriguez-Moreno L, Ballester AR, de Moura MC, Bonghi C, Candresse T, Martinez-Gomez P. Analysis of gene expression changes in peach leaves in response to plum pox virus infection using RNA-seq. Mol Plant Pathol. 2015;16:164-76.

35. Zhu C, Li X, Zheng J. Transcriptome profiling using Illumina- and SMRTbased RNA-seq of hot pepper for in-depth understanding of genes involved in CMV infection. Gene. 2018;666:123-33.

36. Trujillo M, Ichimura K, Casais C, Shirasu K. Negative regulation of PAMPtriggered immunity by an E3 ubiquitin ligase triplet in Arabidopsis. Curr Biol. 2008;18:1396-401.

37. Hu LF, Ye M, Kuai P, Ye MF, Erb M, Lou YG. OsLRR-RLK1, an early responsive leucine-rich repeat receptor-like kinase, initiates rice defense responses against a chewing herbivore. New Phytol. 2018;219:1097-111.
38. Garcia AV, Charrier A, Schikora A, Bigeard J, Pateyron S, de Tauzia-Moreau ML, Evrard A, Mithofer A, Martin-Magniette ML, Virlogeux-Payant I, Hirt H. Salmonella enterica flagellin is recognized via FLS2 and activates PAMPtriggered immunity in Arabidopsis thaliana. Mol Plant. 2014;7:657-74.

39. Kim NH, Hwang BK. Pepper pathogenesis-related protein $4 \mathrm{C}$ is a plasma membrane-localized cysteine protease inhibitor that is required for plant cell death and defense signaling. Plant J. 2015;8:81-94.

40. Constabel CP, Bertrand C, Brisson N. Transgenic potato plants overexpressing the pathogenesis-related $\mathrm{STH}-2$ gene show unaltered susceptibility to Phytophthora infestans and potato virus X. Plant Mol Biol. 1993;22:775-82.

41. Bittner-Eddy PD, Crute IR, Holub EB, Beynon JL. RPP13 is a simple locus in Arabidopsis thaliana for alleles that specify downy mildew resistance to different avirulence determinants in Peronospora parasitica. Plant J. 2000;21:177-88.

42. Bittner-Eddy PD, Beynon JL. The Arabidopsis downy mildew resistance gene, RPP13-Nd, functions independently of NDR1 and EDS1 and does not require the accumulation of salicylic acid. Mol Plant-Microbe Interact. 2001; 14:416-21.

43. Wang A, Hu J, Huang X, Li X, Zhou G, Yan Z. Comparative transcriptome analysis reveals heat-responsive genes in Chinese cabbage (Brassica rapa ssp. Chinensis). Front Plant Sci. 2016;7:939.

44. Oh SK, Baek KH, Park JM, Yi SY, Yu SH, Kamoun S, Choi D. Capsicum annuum WRKY protein CaWRKYY1 is a negative regulator of pathogen defense. New Phytol. 2008;17:977-89.

45. Yang B, Jiang Y, Rahman MH, Deyholos MK, Kav NN. Identification and expression analysis of WRKY transcription factor genes in canola (Brassica napus $\mathrm{L}$.) in response to fungal pathogens and hormone treatments. BMC Plant Biol. 2009;9:68.

46. Dagdas YF, Belhaj K, Maqbool A, Chaparro-Garcia A, Pandey P, Petre B, Tabassum N, Cruz-Mireles N, Hughes RK, Sklenar J. An effector of the Irish potato famine pathogen antagonizes a host autophagy cargo receptor. eLife. 2016;5:e10856.

47. Chiramel Al, Brady NR, Bartenschlager R. Divergent roles of autophagy in virus infection. Cells. 2018:2:83-104.

48. Orvedahl A, MacPherson S, Sumpter R, Talloczy Z, Zou Z, Levine B. Autophagy protects against Sindbis virus infection of the central nervous system. Cell Host Microbe. 2010;7:115-27.

49. Hofius D, Li L, Hafrén A, Coll NS. Autophagy as an emerging arena for plantpathogen interactions. Curr Opin Plant Biol. 2017;38:117-23.

50. Li F, Zhao N, Li Z, Xu X, Wang Y, Yang X, Liu S, Wang A, Zhou X. A calmodulin-like protein suppresses RNA silencing and promotes geminivirus infection by degrading SGS3 via the autophagy pathway in Nicotiana benthamiana. PLoS Pathog. 2017;13:e1006213.

51. Huang YP, Huang YW, Hsiao YJ, Li SC, Hsu YH, Tsai CH. Autophagy is involved in assisting the replication of Bamboo mosaic virus in Nicotiana benthamiana. J Exp Bot. 2019;70:4657-70.

52. Nishida Y, Arakawa S, Fujitani K, Yamaguchi H, Mizuta T, Kanaseki T, Komatsu M, Otsu K, Tsujimoto Y, Shimizu S. Discovery of Atg5/Atg7-independent alternative macroautophagy. Nature. 2009;461:654-8.

53. Abdollahzadeh I, Schwarten M, Gensch T, Willbold D, Weiergraber OH. The Atg8 family of proteins-modulating shape and functionality of autophagic membranes. Front Genet. 2017;8:109.

54. Takatsuka C, Inoue Y, Matsuoka K, Moriyasu Y. Three-Methyladenine inhibits autophagy in tobacco culture cells under sucrose starvation conditions. Plant Cell Physiol. 2004;45:265-74.

55. Moriyasu $Y$, Inoue $Y$. Use of protease inhibitors for detecting autophagy in plants. Methods Enzymol. 2008;451:557-80.

56. Kang R, Zeh HJ, Lotze MT, Tang D. The Beclin 1 network regulates autophagy and apoptosis. Cell Death Differ. 2011;18:571-80.

57. Levine B, Liu R, Dong X, Zhong Q. Beclin orthologs: integrative hubs of cell signaling, membrane trafficking and physiology. Trends Cell Biol. 2015;25: $533-44$

58. Koonin EV, Dolja W. Evolution and taxonomy of positive strand RNA viruses: implications of comparative analysis of amino acid sequences. Crit Rev Biochem Mol Biol. 1993;28:375-430.

59. Yu M, Zhou T, Wu Y, An M. Complete genome sequence of a Pepper mild mottle virus isolate from Northeast China. Genome Announc. 2018;6: e01500-17.

60. Kim D, Pertea G, Trapnell C, Pimentel H, Kelley R, Salzberg SL. TopHat2: accurate alignment of transcriptomes in the presence of insertions, deletions and gene fusions. Genome Biol. 2013;14:R36. 
61. Trapnell C, Williams B, Pertea G, Mortazavi A, Kwan G, van Baren J, Salzberg S, Wold B, Pachter L. Transcript assembly and quantification by RNA-Seq reveals unannotated transcripts and isoform switching during cell differentiation. Nat Biotechnol. 2010;28:511-5.

62. Anders S, Huber W. Differential expression analysis for sequence count data. Genome Biol. 2010;11:1-12.

63. Young MD, Wakefield MJ, Oshlack A, Smyth GK. Gene ontology analysis for RNA-seq: accounting for selection bias. Genome Biol. 2010;11:R14.

64. Wan HJ, Yuan W, Ruan MY, Ye QJ, Wang RQ, Li ZM, Zhou GZ, Yao ZP, Zhao J, Liu SJ, Yang YJ. Identification of reference genes for reverse transcription quantitative real-time PCR normalization in pepper (Capsicum annuum L.). Biochem Biophys Res Commun. 2011:416:24-30.

65. Livak KJ, Schmittgen TD. Analysis of relative gene expression data using real-time quantitative PCR and the $2^{-\Delta \Delta C T}$ method. Methods. 2001;25:402-8.

66. Cao X, Jin X, Zhang X, Li Y, Wang C, Wang X, Hong J, Wang X, Li D, Zhang $Y$. Morphogenesis of endoplasmic reticulum membrane-invaginated vesicles during beet black scorch virus infection: role of auxiliary replication protein and new implications of three-dimensional architecture. J Virol. 2015;89: 6184-95.

67. Gouveia BC, Calil IP, Machado JP, Santos AA, Fontes EP. Immune receptors and co-receptors in antiviral innate immunity in plants. Front Microbiol. 2016;7:2139.

\section{Publisher's Note}

Springer Nature remains neutral with regard to jurisdictional claims in published maps and institutional affiliations.

Ready to submit your research? Choose BMC and benefit from:

- fast, convenient online submission

- thorough peer review by experienced researchers in your field

- rapid publication on acceptance

- support for research data, including large and complex data types

- gold Open Access which fosters wider collaboration and increased citations

- maximum visibility for your research: over $100 \mathrm{M}$ website views per year

At $\mathrm{BMC}$, research is always in progress.

Learn more biomedcentral.com/submissions 